Project 1017633

\title{
New Catalytic DNA Biosensors for Radionuclides and Metal ions
}

\author{
Lu, Yi \\ University of Illinois
}

\begin{abstract}
RESULTS TO DATE: The goals of the project are to develop new catalytic DNA biosensors for simultaneous detection and quantification of bioavailable radionuclides and metal ions, and apply the sensors for on-site, real-time assessment of concentration, speciation and stability of the individual contaminants during and after bioremediation. A negative selection strategy was tested and validated. In vitro selection was shown to yield highly active and specific transition metal ion-dependent catalytic DNA/RNA. A fluorescence resonance energy transfer (FRET) study of in vitro selected DNA demonstrated that the trifluorophore labeled system is a simple and powerful tool in studying complex biomolecules structure and dynamics, and is capable of revealing new sophisticated structural changes. New fluorophore/quenchers in a single fluorosensor yielded improved signal to noise ratio in detection, identification and quantification of metal contaminants. Catalytic DNA fluorescent and colorimetric sensors were shown useful in sensing lead in lake water and in leaded paint. Project results were described in two papers and two patents, and won an international prize.
\end{abstract}

DELIVERABLES: 1. P. J. Bruesehoff, J. Li, A. J. Augustine III, and Y. Lu, Improving Metal Ion Specificity During In Vitro Selection of Catalytic DNA, Combinatorial Chemistry and High Throughput Screening, in press. 2. J. Liu, and Y. Lu, FRET Study of a Tri-fluorophore-labeled Catalytic DNA System Revealed New Metal-Dependent Conformational Changes, submitted to Nature Structural Biology. 3. J. Liu, and Y. Lu, New Fluorescence Based Biosensor, US patent application, submitted on May 10, 2002. 4. J. Liu, and Y. Lu, Simple Catalytic Dna Biosensors for Ions Based on Color Changes, US patent application, submitted on May 10, 2002. 